\title{
KẾT QUẢ HOẠT ĐỘNG CỦA ĐƠN VỊ PHẪU THUẬT TIM MẠCH - LỒNG NGỰC, BỆNH VIỆN ĐẠI HỌC Y HÀ NỘI SAU 1 NĂM THÀNH LẬP
}

Vũ Ngọc Tư , Đoàn Quốc Hung ${ }^{*}$, Nguyê̂n Duy Thắng*, Nguyễn Anh Huy**, Nguyê̂n Duy Gia ${ }^{* *}$

\section{TÓM TẮT}

Mục tiêu nghiên cứu: Đơn vị Phẫu thuật Tim mạch - Lồng ngực (PT TM - LN) mới được thành lập. Tổng kết hoạt động của Đơn vị sau 1 năm có ý nghĩa quan trọng để hoàn thiện qui trình, kĩ thuật và định hướng phát triển trong tương lai.

Đối tượng và phương pháp nghiên cứu: Nghiên cứu theo phương pháp mô tả cắt ngang tất cả bệnh nhân được phẫu thuật tim mạch, lồng ngực trong khoảng thời gian từ tháng 10/ 2019 đến 10/ 2020.

Kết quả: Có 252 ca phẫu thuật, trong đó có 64 ca phẫu thuật tim hở, 70 ca phẫu thuật lồng ngực và 118 ca mổ mạch máu. Phẫu thuật nhiều mặt bệnh đa dạng của tim mạch - lồng ngực, như phẫu thuật lóc động mạch chủ loại $\mathrm{A}$, thay van, sửa van tim, phẫu thuật bệnh lý mạch máu như mạch cảnh, động mạch chủ bụng, thiếu máu mạn tính chi hay các bệnh lý phổi, trung thất, lồng ngực. Các kỹ thuật hybrid (phẫu thuật và can thiệp đồng thời) cho bệnh lý mạch máu chi, bệnh động mạch chủ ...

Kết luận: Qua một năm hoạt động, mặc dù còn nhiều khó khăn và hạn chế, Đơn vị đã triển khai thành công các phẫu thuật chuyên sâu về tim mạch - lồng ngực.

Tù khóa: phẫu thuật tim hở, phẫu thuật lồng ngực, phẫu thuật mạch máu.

OPERATION RESULTS IN NEW DEPARTEMENT OF CARDIOVASCULAR AND THORACIC SURGERY IN HANOI MEDICAL UNIVERSITY HOSPITAL AFTER 1 YEAR ESTABLISMENT ABSTRACT

Objective: The new Cardiovascular and Thoracic Surgery Departement was newly established in 2019. The surgical result is important for the progression of Departement.

Methods: Cross-sectional descriptive stud in period of 1 year (from October 2019 to October 2020).

Results: We have perfomed 252 operations. including 64 open-heart surgeries, 70 thoracic surgeries and 118 blood vessel operations. In terms of disease, we have performed surgery on many cardiac diseases, such as type A aortic dissection, valve replacement, heart valve repair, vascular pathology such as carotid artery abdominal aorta, chronic limb anemia or lung, mediastinal or thoracic pathology. In addition, the departement has also initially implemented hybrid techniques (surgery and percutaneous intervention) for limb vascular disease, aortic disease...

Conclusions: Over a year of operation, despite many difficulties and limited, the departement has successfully implemented specialized cardiovascular and thoracic surgery.

Key words: cardiac surgery, thoracic surgery, vascular surgery.

\section{TỔNG QUAN}

Tại Bệnh viện Đại học Y Hà Nội, song song với nhu cầu phát triển chuyên môn sâu của các chuyên ngành ngoại khoa cũng như sự phát triển không ngừng của Trung tâm Tim mạch, nhu cầu phát triển phẫu thuật tim mạch - lồng ngực

\footnotetext{
* Truờng Đại học Y Hà Nội.

** Trung tâm Tim mach, Bệnh viện Đại học Y Hà Nội

Nguoòi chịu trách nhiệm khoa học: Vũ Ngoc Tú
}

Ngày nhận bài: 29/12/2020 - Ngày Cho Phép Đăng: 27/01/2021 
cũng được đặt ra. Trong đó, việc triển khai phẫu thuật tim hở đòi hỏi nhiều sự chuẩn bị cả về cơ sở vật chất, nhân lực của nội khoa tim mạch, phẫu thuật viên, kỹ thuật viên chạy máy tim phổi nhân tạo, gây mê và hồi sức tim.

Qua một năm triển khai và hoạt động, Đơn vị PT TM - LN đã bước đầu thực hiện thường qui phẫu thuật tim hở, bên cạnh các phẫu thuật lồng ngực, mạch máu đã được thực hiện từ trước đây để giải quyết nhu cầu điều trị bệnh nhân và phát triển chuyên môn.

Chúng tôi tổng kết 256 ca phẫu thuật trong vòng 1 năm vừa qua của Đơn vị và đưa ra những nhận xét về những kết quả, khó khăn để từ đó rút kinh nghiệm, đưa ra phương hướng hoạt động và phát triển hợp lý trong thời gian tới.

\section{II. ĐỐI TƯợNG VÀ PHƯƠNG PHÁP}

Nghiên cứu được tiến hành theo phương pháp mô tả cắt ngang, lựa chọn tất cả các bệnh nhân được thực hiện các phẫu thuật về tim mạch và lồng ngực tại Bệnh viện Đại học $\mathrm{Y}$ Hà Nội từ tháng 10 năm 2019 đến tháng 10 năm 2020, có đầy đủ thông tin hồ sơ bệnh án.

\section{KẾT QUẢ}

Trong khoảng thời gian từ tháng 10 năm 2019 đến tháng 10 năm 2020, chúng tôi đã tiến hành 252 ca phẫu thuật tim, lồng ngực, mạch máu, trong đó có 4 được thực hiện đồng thời phẫu thuật và can thiệp (hybrid). Tuổi trung bình: 52,3 (cao nhất: 91, nhỏ nhất: 7), tỉ lệ nam/ nữ =1,7.

\subsection{Phân bố các bệnh lý tim mạch, lồng ngực được phẫu thuật}

Biểu đồ 1.1: Các bệnh lý tim mạch - lồng ngực được phẫu thuật $(N=252)$

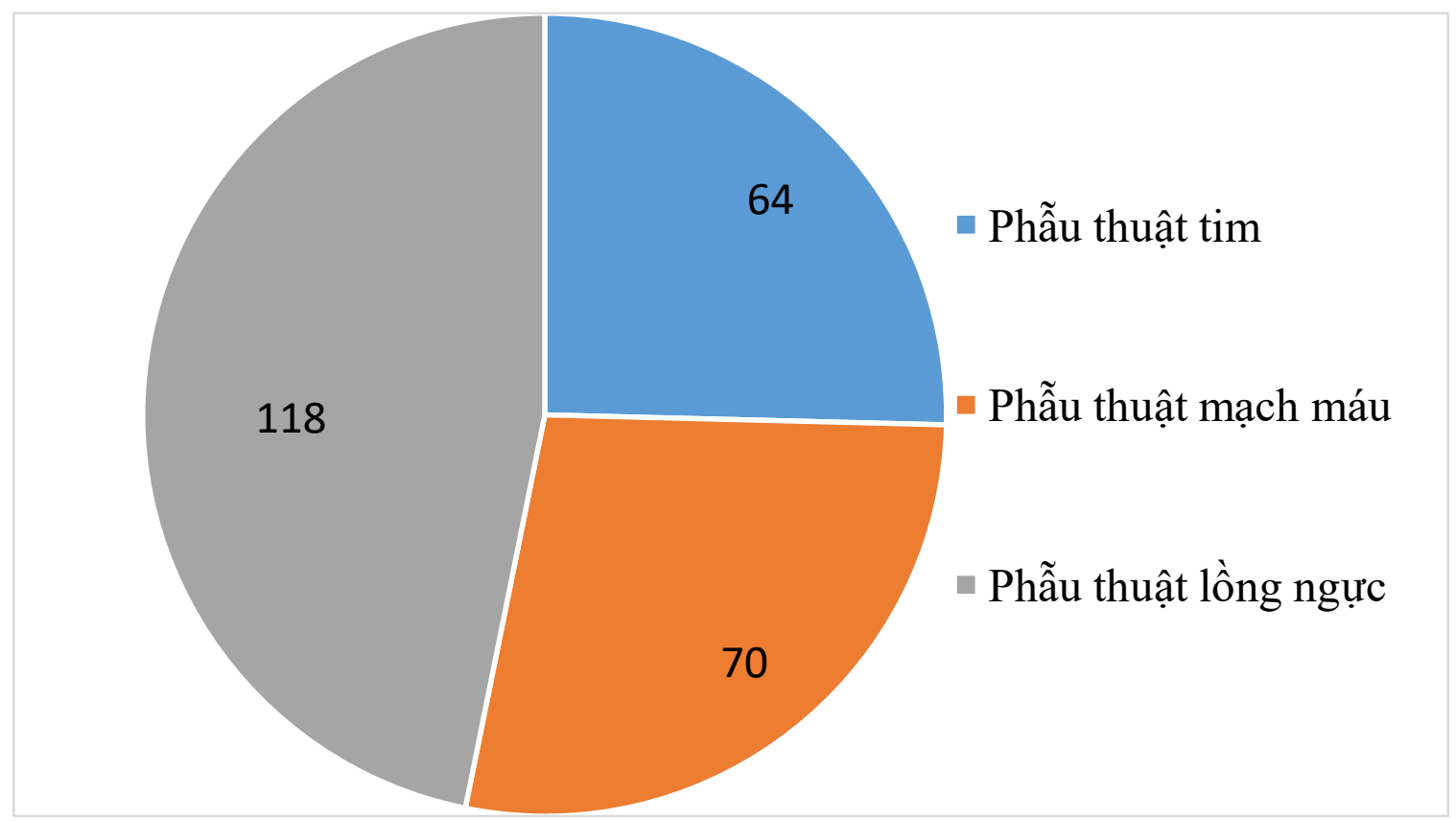

Nhận xét: Phẫu thuật lồng ngực (gồm cả bệnh lý cổ - nền cổ) chiếm $46,1 \%$, phẫu thuật tim chiếm 25,0\%, và phẫu thuật mạch máu chiếm 27,3\%. 


\subsection{Phẫu thuật tim}

Bảng 1.1: Các bệnh lý tim được phẫu thuật $(N=64)$

\begin{tabular}{|c|l|c|}
\hline Loại phẫu thuật tim & \multicolumn{1}{|c|}{ Bệnh lý tim được phẫu thuật } & Số lượng \\
\hline \multirow{2}{*}{$\begin{array}{c}\text { Phẫu thuật tim kín } \\
(8)\end{array}$} & $\begin{array}{l}\text { Chấn thương, vết thương tim, viêm màng ngoài } \\
\text { tim co thắt } \\
\text { Động mạch chủ ngực }\end{array}$ & 6 \\
\hline \multirow{5}{*}{$\begin{array}{c}\text { Phẫu thuật tim hở } \\
\text { (56) }\end{array}$} & Thay van tim & 29 \\
\cline { 2 - 3 } & Sửa van tim & 10 \\
\cline { 2 - 3 } & Bắc cầu mạch vành & 4 \\
\cline { 2 - 3 } & Lóc động mạch chủ loại A & 2 \\
\cline { 2 - 3 } & Tim bầm sinh & 6 \\
\cline { 2 - 3 } & U tim & 4 \\
\hline
\end{tabular}

Nhận xét: Hấu hết trong số bệnh nhân phẫu thuật tim là phẫu thuật tim hở (56 bệnh nhân, chiếm $87,5 \%$. Có 29 bệnh nhân thay van, chiếm $51 \%$ số bệnh nhân mổ tim hở. Có 10 bệnh nhân được sửa van, chiếm $17,8 \%$.

\subsection{Phẫu thuật mạch máu}

Bảng 1.2: Các bệnh lý mạch máu được phẫu thuật $(N=70)$

\begin{tabular}{|l|c|}
\hline \multicolumn{1}{|c|}{ Phẫu thuật } & Số lượng \\
\hline Thay đoạn động mạch chủ bụng & 8 \\
Phẫu thuật bóc nội mạc do hệp động mạch cảnh & 6 \\
\hline Lấy huyết khối, bắc cầu do bệnh lý mạch máu chi (cấp - mạn tính) & 16 \\
Chấn thương, vết thương mạch chi & 15 \\
\hline Mở động mạch đùi đặt để thực hiện can thiệp qua da & 13 \\
\hline Khác (tạo AVF, lột tĩnh mạch hiển, động mạch tạng ...) & 12 \\
\hline
\end{tabular}

Nhận xét: Phẫu thuật bệnh lý và chấn thương, vết thương mạch máu chi chiếm số lượng nhiều nhất.

\subsection{Phẫu thuật lồng ngực, cổ}

Bảng 1.3: Các bệnh lý lồng ngưcc, cổ - nền cổ được phẫu thuật $(N=118)$

\begin{tabular}{|l|c|c|}
\hline \multicolumn{1}{|c|}{ Phẫu thuật } & Số lượng & $\begin{array}{c}\text { Phẫu thuật } \\
\text { nội soi }\end{array}$ \\
\hline Cắt thùy phổi do u phổi & 21 & 21 \\
Cắt u trung thất & 15 & 15 \\
\hline Chẩn đoán bệnh lý phổi, trung thất & 18 & 17 \\
Cắt kén khí phổi & 7 & 7 \\
\hline Đốt hạch giao cảm điều trị ra mồ hôi tay & 12 & 12 \\
\hline Máu cục - ồ cặn khoang màng phổi & 15 & 3 \\
\hline $\begin{array}{l}\text { Cổ - nền cố } \\
\text { (U tuyến giáp, u máu - bạch huyết, vết thương nền cổ ...) }\end{array}$ & 13 & - \\
\hline $\begin{array}{l}\text { Khác (lấy nhân di căn phổi, dị vật phổi, đứt dây chằng đỉnh } \\
\text { phổi, tạo hình thành ngực, chấn thương, vết thương ngực) }\end{array}$ & 17 & - \\
\hline
\end{tabular}

Nhận xét: Phẫu thuật điều trị bệnh lý u phổi và u trung thất chiếm tỷ lệ cao nhất và hầu hết bệnh nhân được phẫu thuật nội soi. 


\section{BÀN LUẬN}

\subsection{Phẫu thuật tim hở}

Trung tâm Tim mạch, Bệnh viện Đại học Y Hà Nội hình thành và hoạt động đã từ hơn 10 năm nay, với số lượng người bệnh ngày càng tăng. Bênh cạnh điều trị nội khoa và can thiệp chuyên sâu nhiều bệnh lý phức tạp, không ít trường hợp đòi hỏi phải chỉ định điều trị phẫu thuật, thậm chí phẫu thuật cấp cứu tim hở (do bản chất bệnh hoặc do quá trình điều trị nội khoa, can thiệp có biến chứng) [1]. Một khi không triển khai được phẫu thuật tim hở, người bệnh sẽ phải chuyển đến các Trung tâm khác, dẫn đến kéo dài quá trình xử trí, làm giảm hiệu quả điều trị, thậm chí dẫn tới tử vong. Đứng trước thực tế này, từ cuối năm 2019, Đơn vị Phẫu thuật Tim mạch và Lồng ngực thuộc Trung tâm Tim mạch đã được thành lập với nhiệm vụ trọng tâm là phẫu thuật tim hở.

Chúng tôi đã thực hiện 64 ca phẫu thuật

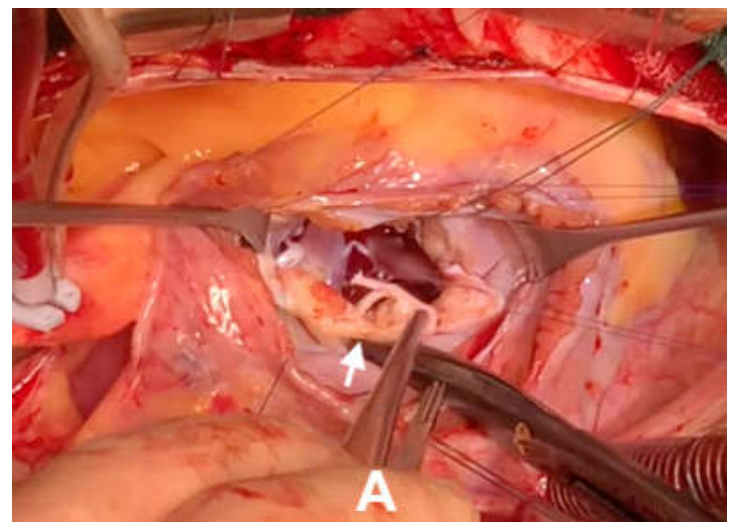

tim, với 56 ca phẫu thuật tim hở. Đây là số lượng phẫu thuật tương đối nhỏ so với các trung tâm phẫu thuật tim lớn của cả nước. Tuy nhiên, độ phức tạp về bệnh lý, kĩ thuật phẫu thuật cũng như gây mê hồi sức cũng tương tự như các đơn vị mổ tim khác như: phẫu thuật lóc động mạch chủ loại $\mathrm{A}$, phẫu thuật cho bệnh nhân lớn tuổi (cao nhất 83), bệnh lý van tim có suy tim phải nặng, phẫu thuật cấp cứu tim hở.... Phẫu thuật thay van chiếm tỷ lệ cao nhất với $29 \mathrm{ca}$, chiếm tỷ lệ $51,7 \%$. Ngoài ra, tỷ lệ số phẫu thuật sửa van chiếm gần $20 \%$, cao hơn của một số tác giả [2], hầu hết trong số này là phẫu thuật sửa van hai lá (Hình 1). Điều này cho thấy những mặt bệnh liên quan đến chỉ định sửa van như thoái hóa van, viêm nội tâm mạc ... chiếm tỷ lệ ngày càng cao [3]. Cùng với đó, sự tiến bộ của chẩn đoán trước mổ cũng như sự phối hợp hiệu quả của siêu âm tim qua thực quản trong mổ cũng góp phần nâng cao tỷ lệ bệnh nhân chỉ định và sửa van thành công của chúng tôi.

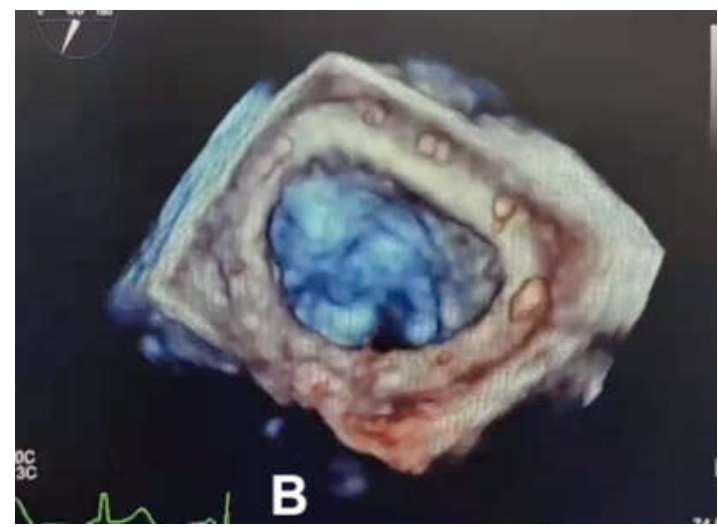

Hình 1: Sửa van hai lá: A-Cắt bỏ vùng lá sau tổn thuoong sùi, đứt dây chằng; $B$ - Hình ảnh van hai lá có vòng van trên siêu âm tim $3 D$ qua thực quản trong mổ

Về bệnh lý động mạch chủ ngực, có 2 trường hợp lóc động mạch chủ loại $\mathrm{A}, 2$ trường hợp phồng động mạch chủ lên. Tất cả các trường hợp lóc động mạch chủ loại $\mathrm{A}$ đều được phẫu thuật dưới hạ thân nhiệt, ngừng tuần hoàn nửa dưới cơ thể và tưới máu não chọn lọc. Để theo dõi và chủ động khi thực hiện tưới máu não chọn lọc, ngoài các thông số về lưu lượng bơm động mạch từ máy tim phổi nhân tạo, áp lực dòng máu tại gốc động mạch cảnh, chúng tôi còn sử dụng các điện cực theo dõi độ bão hòa oxy não. Đây chính là yếu tố quan trọng giúp cải thiện tình trạng thần kinh sau mổ của người bệnh, qua đó giảm thời gian thở máy và nằm hồi sức. 
Trong số những bệnh nhân mổ tim hở, có 1 trường hợp nặng xin về không tiếp tục điều trị. Đây là bệnh nhân được phẫu thuật cấp cứu bắc cầu chủ vành do nhồi máu cơ tim cấp, có rung thất và cấp cứu ngừng tuần hoàn. Sau phẫu thuật tình trạng huyết động ổn định, diễn biến nặng là do tình trạng thiếu máu não tiến triển từ trước mổ.

\subsection{Phẫu thuật mạch máu}

Phẫu thuật mạch máu cũng đã được thực hiện cho nhiều mặt bệnh khác nhau, bao gồm hầu hết các bệnh lý mạch máu thường gặp là phồng động mạch chủ bụng, hẹp tắc động mạch cảnh, thiếu máu cấp tính, mạn tính chi... Hiện nay, tại Trung tâm Tim mạch, Bệnh viện Đại học Y Hà nội cũng như nhiều Trung tâm Tim mạch khác tại Việt Nam, các kĩ thuật can thiệp mạch máu ngày càng được áp dụng rộng rãi, do đó một phần không nhỏ người bệnh phồng động mạch chủ bụng, hẹp động mạch cảnh ... được xử lý can thiệp qua da thay vì phẫu thuật [4]. Tuy nhiên, khi kĩ thuật can thiệp khó khăn hoặc chống chỉ định, phương pháp phẫu thuật lại có những ưu thế rõ rệt, đặc biệt là với sự hồ trợ tối đa từ chuyên khoa gây mê hồi sức. Chính vì vậy, chúng tôi đã thực hiện được phẫu thuật thay thế đoạn động mạch chủ chậu nhân tạo thành công cho bệnh nhân cao tuổi nhất trong nghiên cứu này (91 tuổi) có bệnh lý phồng động mạch chủ chậu, với phồng động mạch chậu trong hai bên lớn $(5-6 \mathrm{~cm})$ phải thắt các động mạch này, kèm theo bảo tồn được động mạch mạc treo tràng dưới để giảm thiểu nguy cơ hoại tử ruột.

\subsection{Phẫu thuật và can thiệp đồng thì (hybrid)}

Trung tâm Tim mạch, Bệnh viện Đại học Y Hà Nội cũng là một trong những đơn vị can thiệp lớn thực hiện thường qui các kĩ thuật can thiệp điều trị bệnh tim bẩm sinh, mắc phải cũng như các bệnh lý động mạch chủ, động mạch vành và động mạch ngoại vi. Sự ra đời của Đơn vị Phẫu thuật Tim mạch - Lồng ngực giúp cho Bệnh viện có thể chủ động và triển khai thường qui các kĩ thuật hybrid. Có hai dạng kĩ thuật hybrid chính mà chúng tôi đã thực hiện thành công.

Dạng thư nhất: thực hiện kĩ thuật hybrid trong phẫu thuật động mạch chủ ngực cho bệnh nhân lóc động mạch chủ loại $\mathrm{A}$, kèm lóc, phồng động mạch chủ xuống. Cùng với thay thế động mạch chủ lên và toàn bộ quai động mạch chủ, giá đỡ có phủ được đặt vào trong lòng động mạch chủ xuống. Kĩ thuật này còn gọi là kĩ thuật "vòi voi đông cứng" (Hình 2). Đây là một phẫu thuật lớn, thời gian mổ kéo dài, đòi hỏi hạ thân nhiệt, ngừng tuần hoàn, tưới máu não chọn lọc dẫn tới nguy cơ chảy máu, suy tạng, biến chứng não, tử vong... sau mổ cao. Với sự chuẩn bị chuẩn bị đầy đủ, chuyên nghiệp và sự phối hợp chặt chẽ của các chuyên khoa sâu, chúng tôi đã thực hiện thành công kĩ thuật trên, người bệnh an toàn và khỏe mạnh khi ra viện.


Hình 2: Kũ thuật hybrid cho lóc động mạch chủ loại A: A-Đặt giá đõ có phủ (stent graft) cho động mạch chủ xuống (mũi tên); B - Phẫu thuật thay toàn bộ quai động mạch chü; C: Hình ảnh chup MSCT động mạch chủ sau mổ (1: mạch nhân tạo, 2: giá đõ có phủ) 
Dạng thư hai: thực hiện kĩ thuật hybrid với bệnh lý thiếu máu chi, thường áp dụng cho những trường hợp tổn thương mạch nhiều tầng, với tầng trên tại động mạch chủ - chậu, tầng dưới tổn thương tại động mạch đùi, khoeo. Trường hợp chúng tôi thực hiện có tổn thương tắc mạn tính hoàn toàn động mạch chậu chung và chậu ngoài kèm hẹp khít động mạch đùi nông bên trái. Bệnh nhân được thực hiện đồng thời phẫu thuật bắc cầu động mạch chủ - động mạch đùi (tại ngã ba động mạch đùi nông - sâu) bằng mạch nhân tạo và qua vị trí mở mạch nong động mạch đùi nông. Sau phẫu thuật, hệ thống mạch máu chi thông, tưới máu chi được cải thiện rất tốt.

\subsection{Phẫu thuật lồng ngực}

Phẫu thuật $\mathrm{u}$ phổi chiếm tỷ lệ cao nhất $(20,4 \%)$. Ung thư phổi có tỷ lệ mắc và tử vong hàng đầu ở Việt Nam, cùng với đó là sự tiến bộ trong những năm gần đây trong việc nâng cao ý thức của cộng đồng và các phương tiện tầm soát, nên tỷ lệ bệnh nhân ung thư phổi ở giai đoạn sớm, có thể phẫu thuật cũng đang ngày tăng lên [5]. Tất cả các trường hợp u phổi đều được thực hiện cắt thùy phổi qua nội soi hỗ trợ.

Song với đó, tỷ lệ bệnh nhân được phẫu thuật nội soi lồng ngực để chẩn đoán của chúng tôi cũng có tỷ lệ tương đối cao (18 trường hợp, chiếm $16,7 \%$ ), hầu hết là các trường hợp tràn dịch màng phổi nghi do lao. Tỷ lệ này cao hơn những cơ sở khác trong các nghiên cứu trước đây, như tại bệnh viện Thống Nhất giai đoạn 2009 - 2012 [6], đồng thời tương đương với những nghiên cứu gần đây về nội soi chẩn đoán lồng ngực [7]. Điều này có thể giải thích là do tỷ lệ bệnh nhân nhiễm lao xét nghiệm âm tính ngày càng nhiều, dẫn đến nhưng kết quả sinh thiết xuyên thành hay xét nghiệm dịch màng phổi gặp nhiều khó khăn hơn trong việc chẩn đoán bệnh. Với tiến bộ của kỹ thuật phẫu thuật nội soi, nội soi chẩn đoán và sinh thiết tức thì trong mổ là một biện pháp xâm lấn tối thiểu, giúp đưa ra quyết định điều trị chính xác nhất cho người bệnh.

\section{KÊT LUẬN}

Trong khoảng thời gian 1 năm từ tháng 10 năm 2019 đến tháng 10 năm 2020, chúng tôi đã triển khai thành công mổ tim hở với 56 ca phẫu thuật. Đồng thời, chúng tôi cũng tiếp tục đẩy mạnh phẫu thuật mạch máu, lồng ngực, nâng cao cả về số lượng và độ đa dạng của mặt bệnh.

Với lợi thể của một bệnh viện đa chuyên khoa, Đơn vị Phẫu thuật Tim mạch - Lồng ngực, bệnh viện Đại học Y Hà Nội cũng có được sự phối hợp của nhiều chuyên ngành khác, giúp triển khai các kỹ thuật mới, góp phần nâng cao chất lượng điều trị và đông góp cho sự phát triển chung của chuyên ngành phẫu thuật tim mạch - lồng ngực cũng như sự phát triển chung của bệnh viện.

\section{TÀI LIỆU THAM KHẢO}

1. Vũ Ngọc Tú, Lê Minh Ngọc, Nguyễn Thị Minh Lý et al. (2020). Phẫu thuật cấp cứu tim hở tại Bệnh viện Đại học Y Hà Nội. Tạp chí Nghiên cứu y học, tr.134, 102-108.

2. Lâm Việt Triều, Hà Bửu Kiếm, Phạm Thanh Phong et al. (2018). Bước đầu đánh giá kết quả triển khai kĩ thuật mổ tim hở tại Bệnh viện Đa khoa Trung ương Cần Thơ. Phẫu thuật tim mạch và lồng ngực Việt Nam, 20, 72-74.

3. (2016). Heart valve disease, epidemiology module. The British Journal of Cardiology, 03,

4. Đinh Thị Thu Hương, Nguyễn Tuấn Hải, và tiểu ban mạch máu (2010). Khuyến cáo 2010 
của hội tim mạch học Việt Nam về chẩn đoán và điều trị bệnh động mạch chi dưới. Khuyến cáo 2010 về các bệnh lý tim mạch và chuyển hóa, 163-192.

5. Thuan V. Tran, Chi T. Du Tran (2018). Cancer epidemiology research in Vietnam: Current status, challenges and opportunities. AACR Annual Meeting, 78.

6. Nguyễn Đỗ Nhân, Trần Văn Sơn
(2012). Nhận xét bước đầu về nội soi lồng ngực chẩn đoán và điều trị bệnh lý màng phổi ở người cao tuổi tại bệnh viện Thống nhất. Tạp chí Nghiên cứu Y học Y Học TP. Hồ Chí Minh, 16,

7. Đ.V.Tuấn (2018). Vai trò của phẫu thuật nội soi lồng ngực kín trong điều trị sớm các di chứng tràn dịch màng phổi do lao tại Bệnh viện Phổi Trung ương. Kỷ yếu hội nghị Hô hấp Pháp - Việt, 70. 